\title{
Valuing watershed services: concepts and empirics from southeast Asia
}

\author{
Subhrendu K. Pattanayak* \\ Health, Social and Economics Research Division, Research Triangle Institute, 3040 Cornwallis Road, \\ Research Triangle Park, NC 27709-2194, USA
}

\begin{abstract}
Few empirical studies have rigorously analyzed the downstream economic benefits of watershed protection to generate economic values of watershed services. By developing a conceptual framework and using household level economic and environmental data to illustrate its empirical tractability, this paper addresses the neglected, but critical, question of the importance of watershed services to farming communities in southeast Asia. A case study from Flores, Indonesia provides evidence of a substantive, quantified economic benefit of watershed service based on a fixed-effects regression model of water collection costs. The paper also offers lessons for researchers at all stages of data collection and analysis and a research agenda for enhancing our toolkit for policy analysis. This discussion of conceptual, empirical and methodological issues collectively suggests that ecosystem valuation can provide critical input into the design and evaluation of conservation and development policies in the tropics. (C) 2004 Elsevier B.V. All rights reserved.
\end{abstract}

Keywords: Economic-ecological modeling; Watershed protection; Drought mitigation; Valuation; Collection costs; Tropical deforestation; Indonesian national parks; Southeast Asia

\section{Introduction}

"The problem of analysis and management of watersheds is fundamentally one of mixed impacts, mixed institutional jurisdictions, mixed signals as to what are costs and benefits... The economist examines the economic implications of alternatives, calculates the costs and benefits of each... [and thus] helps in the policy maker's search for effective, efficient and equitable solutions to land and water resources management" (Dixon, 1997, p. 353).

Economists contend that unreliable information regarding the value of services from tropical forests can partly cause the rapid disappearance of the world's natural forest cover and therefore endanger the flow

* Tel.: +1-919-541-7355; fax: +1-919-541-6683.

E-mail address: subrendu@rti.org (S.K. Pattanayak). of socially useful goods and services from standing forests. Watershed services such as mitigation of floods, droughts, and soil erosion by protected tropical forests are examples of unpriced and undervalued 'life support services' resulting from natural ecosystem functions (Freeman, 1996) that can serve as beneficial inputs to economic livelihoods in the tropics (Dixon, 1997; Dasgupta, 2001).

Public protection of tropical forest watersheds is necessary because the market mechanism cannot provide optimal levels of watershed services. Watershed services will not be traded in the market for several reasons. Their quasi-public good feature implies that it is difficult, if not impossible, to exclude an individual from using watershed services (e.g. drought control), and several individuals can use the services simultaneously without diminishing each other's use values. Their externality feature means that the effect 
on economic profit and utility of users of these services (e.g. soil conservation) will not necessarily enter the decision calculus of the supplier of the services. Typically, these services are characterized by economies of scale in production and consumption, and by transaction costs in the form of incomplete information about the nature and magnitude of their value.

The level of public support for watershed protection depends on the net benefits of providing these services. Recent reviews of surveys of valuation studies reveal, however, that economic benefits of protected watersheds are rarely quantified (Georgiou et al., 1997; Dixon, 1997). This paper attempts to unravel what Dixon describes as the 'mixed impacts and mixed signals' of watershed management by (a) reviewing the ecological and economic literature on watershed services, (b) describing a framework for estimating watershed service benefits, (c) presenting a case study that applies the proposed method to a specific watershed service, and (d) evaluating the valuation framework.

\subsection{Influence of forests on soil and hydrological processes}

Forests are an important component of watershed protection because they maintain soil stability and water quality, enhance nutrient and water use efficiency, and stabilize the hydrological cycle (Pereira, 1989; Lal, 1993). When forest conversion is followed by land uses that interfere and alter natural bio-physical processes, it is the land use, rather than the forest removal per se, that is blamed for the adverse soil and hydrological consequences of deforestation. The relationship between forested land uses in the tropics and watershed services is surveyed in four studies: Hamilton and King (1983), Pereira (1989), Bruijnzeel (1990), and Bonell and Balek (1993). The broad conclusions of these surveys regarding the provision of five watershed services by forest is discussed in comparisons with other land uses that follow deforestation, e.g. mechanized forestry or agriculture, grasslands for grazing, open cast mining, roads, landings, and agriculture. Each service has a distinctly utilitarian character because the primary economic interest is in the effect of watershed services on human welfare (Easter et al., 1990).

\subsubsection{Erosion control}

The presence of a well developed understory or litter layer, typically found under forests, minimizes surface erosion. Further, in the case of forested hillslopes, the greater slope stability imparted by the root network of well developed trees reduce the number of shallow mass movements.

\subsubsection{Enhanced soil quality}

The forest canopy and the litter layer protect the soil from the damaging influence of solar radiation and rainfall. As a result forest soils usually have very open structure and higher concentrations of organic matter and faunal activity, thereby improving access to nutrients and water in the deeper soil profile for trees, plants and other flora.

\subsubsection{Increase in total water yield}

Even though both natural and planted forests use more water than most agricultural crops and grasslands, the better infiltration and water storage capacities of the surface layers of forest soils may result in higher levels of flow, i.e., net of evapotranspiration.

\subsubsection{Stabilization of streamflow distribution}

While the effect of forested watersheds on the hydrological cycle is complicated, stormflow and evapotranspiration are the two most important components of the hydrological system affected by forests. The effects on evapotranspiration and stormflow are determined primarily by the geometry of the forest canopy, the eco-physiology of the dominant tree species, the litter layer, and the below ground soil structure of forests. Under conditions of severe erosion or soil compaction following forest clearing, the ability of the soil to absorb water may be so reduced that dry season baseflow and ground water levels are not maintained and the area faces drought conditions. With regards to floods, forested areas usually register a lower frequency and rate of peakflow for small and medium size storms. For large river basins and big storms, however, other geological and climatic factors are more important than the presence of forest cover.

\subsubsection{Control of sediment in streams}

By reducing soil erosion, forest cover decreases the sedimentation and dissolved load in surface runoff and interflow. However, due to the complex trapping and 
storing process for sediments, there may be significant time lags before downstream sediment loads are noticeably lower in large basins.

The effect of forests on watershed services is imprecise, and the surveys differ mostly in their assessment of the extent of the soil and hydrological influences of forests. Nevertheless, there is a general consensus that forests play a protective role in various watershed processes that is perceptible only at certain temporal and spatial scales (Lal, 1993). In summary, forests enhance overall watershed quality by mitigating the adverse consequences of natural and human disturbances of small intensities at the meso-scale (less than $500 \mathrm{~km}^{2}$ ) with time lags. Because individual farming households are small in comparison to the time and space context of the watershed services discussed above, these services can significantly benefit the typical user of the tropical watersheds (Dixon, 1997; Doolette and Magrath, 1990; Pereira, 1989). For example, even if forests mitigate only small flood events, the benefit to the poor and resource dependent farming household can be immense.

\subsection{Previous economic studies of watershed services}

Economic analyses of watershed services have typically concentrated on soil erosion effects (Georgiou et al., 1997; IIED, 1994). A good example of this is a recent summary article on the analysis and management of watersheds by Dixon (1997). While Dixon mentions all five watershed services, he only discusses analytical methods and economic values of soil erosion and sedimentation, primarily because analyses of other watershed services, such as streamflow stabilization, water quality and quantity effects are rare-particularly for the tropics.

The lack of empirical applications is surprising because the watershed services are similar to the 'water project derivatives' (flood control, navigation, irrigation, hydroelectric power) analyzed in the mid 1960s (Krutilla and Eckstein, 1958; Maas et al., 1962). During this era, attention was on practical issues such as multiple purposes of river development, the optimum (size, sequence and timing of projects), and the conjunctive uses of surface water and ground water resources, i.e., issues of viability, as pointed out by a reviewer. Two distinctions between those "water derivatives' and our 'watershed services', may explain this apparent discontinuity in economic studies. First, traditionally watershed management had a strong hydrologic focus, particularly on the structural (engineering) practices to control the quantity, quality, and timing of water flows. In contrast, tropical watershed management has had broader socio-economic objective, often relying on non-structural (vegetative) practices to generate soil and hydrologic benefits. Second, while the 'water derivatives' were generated by sizeable public investments, watershed services in developing countries result from a more subtle management of forested watersheds. Because planning for integrated water resources projects required great amounts of data and technical expertise, comprehensive economic evaluations of the projects were feasible.

Although some economists (Gregersen et al., 1987; Easter et al., 1986) have proposed conceptual frameworks for economic appraisal of watershed management projects, by building on the Eckstein's (1958) early insights, rigorous empirical applications of their guidelines and conceptual models are scarce and have focused on soil erosion.

Empirical economic analyses of soil erosion have used resource accounting approaches (Clark et al., 1985; Magrath and Arens, 1989), econometric production functions methods (Crosson and Stout, 1983; Walker, 1982) or mathematical programming models (Burt, 1981; Ribaudo, 1989). A resource accounting approach is characterized by project evaluation in which intertemporal cash-flows are generated using parametric economic values drawn from secondary sources. In the econometric approach, production functions are estimated to relate agricultural production to soil erosion. Typically, the production functions are either aggregative (nation or statewide), thereby losing site-specific details, or simple with just two or three arguments. The mathematical programming approach seeks an optimum given an objective function that is subject to constraints with pre-determined parameters. In all cases the value of soil erosion is estimated in terms of its effect on economic productivity.

Our proposed approach also draws on empirical analyses of two classes of ecosystem services, most subject to economic analyses: (a) wetlands services (Swallow, 1994; Lynne et al., 1981), (b) ozone pollution (Kopp et al., 1985; Garcia et al., 1986). In both cases, some proxy for the ecosystem service (e.g. 
saline concentrations in estuarine wetlands or ozone concentrations in farming counties) is related to a production activity (e.g. shrimp or corn) and the value of the ecosystem service is estimated as the incremental profits (lowered production costs).

\section{Analytical framework}

The economic principles for valuation are straightforward (Eckstein, 1958; Mäler, 1991) and can be viewed as the outcome of three sets of functional relationships (Freeman, 1993). Public policies combined with private decisions affect forested watersheds, change watershed flows, and, thereby, generate changes in watershed services. These services affect private production activities of economic agents and consequently their economic welfare. The change in welfare, evaluated in terms of market prices of private commodities, is the use value of watershed services. Although several authors have proposed variations of this framework for the valuation of watershed protection benefits (Haveman, 1972; Gregersen et al., 1987), the analytical and empirical requirements for testing this logic have not been fully specified. Using three general structural equations, below we elaborate on this three-stage analytical framework.

\subsection{Three-stage approach}

Because we conceive of watershed services as producer goods, the values of watershed services are calculated in terms of increases in household incomes or savings in household expenditures. The three arrows in Fig. 1 correspond to Stages 1-3, in which the policy, bio-physical and economic relationships are derived. The first stage in Fig. 1 relates some measure of watershed service, $W_{i}$, to public and private land use, $T_{\mathrm{g}}$ and $T_{i}$-decisions that are amenable to public policy, G (Eq. (1))

Stage 1: $\quad W_{i}=W\left(T_{\mathrm{g}}, T_{i}(G) ; \tau, Z_{\mathrm{w} i}\right)$

$W_{i}$ is a vector of watershed services that can be measured by quantity or rates of any of four measures of soil and water: runoff, streamflow, erosion, and sediment. These natural processes can be affected directly by public policies such as national parks and federal

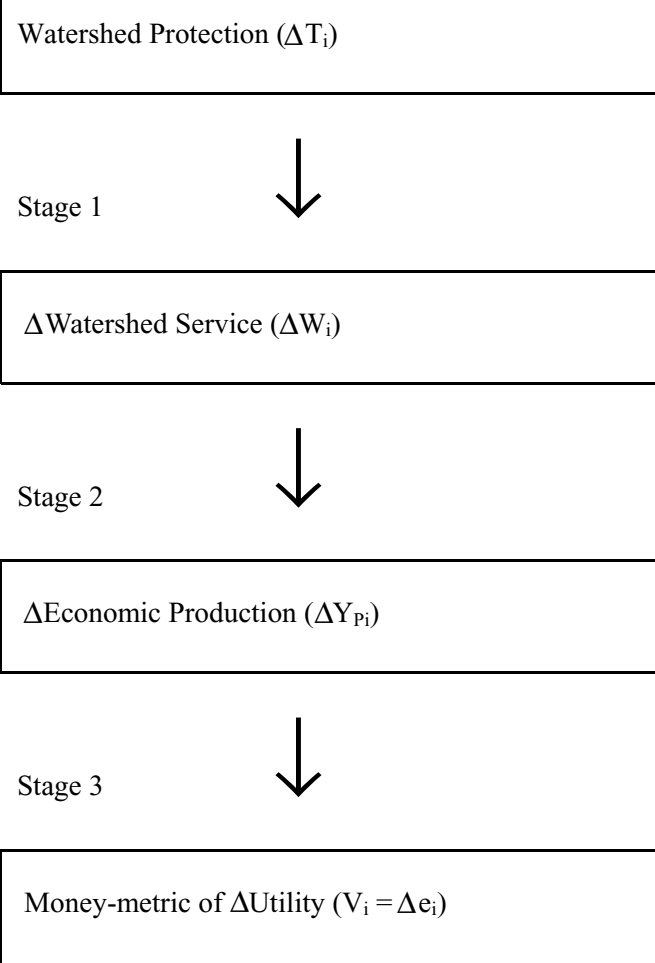

Fig. 1. Conceptual framework for valuation of watershed services.

watershed management that increase the vegetation cover, $T_{\mathrm{g}}$. Private choices, $T_{i}$ (e.g. number of trees or agroforestry practice on farmland) also generate watershed services. The latter choices can also be indirectly influenced by public policies, $G$, such as subsidies, taxes, and provision of information, technical expertise and credit. The variable $\tau$ measures the time lag between a change in land use and its bio-physical effects. The vector $Z_{\mathrm{w} i}$ is comprised of environmental characteristics, including geologic substrate (soil type), topography (aspect, slope and elevation), and climate (rainfall and temperature). Thus, $Z_{\mathrm{w} i}$ captures the influence of various bio-physical factors on the provision of watershed services.

Physical process-based models from agricultural and forest hydrology can be used to establish the structural relationship described in Eq. (1) (Moore et al., 1991; Lal, 1993). This equation could be used to simulate the change in watershed service that can be expressed as the difference, $\Delta W_{i}$, between a baseline (or natural rate), $W_{0}$, and elevated level, $W_{1}$, of 
watershed service. (In this regard, change in watershed services, $\Delta W_{i}$, represents a change (watershed service) in a change (watershed stock). For example, while floods are a change in water levels (stock), flood control is a change in the flood levels (flow), i.e. a change in a change in water levels. Direct and indirect public policies, thus, provide the institutional or policy setting, which cause changes in watershed services, and variations in policy impacts within the available data set enable the analyst to compute values. Exclusive private provision, without any public support $(G)$ is not typical because of the inherent characteristics of the provision process and of the watershed services themselves.

The second stage in Fig. 1 quantifies human use of the watershed service (Eq. (2))

Stage 2: $\quad Y_{\mathrm{P} i}=Y\left(X_{\mathrm{L} i}, W_{i}, Z_{\mathrm{P} i}\right)$

Households use the non-market watershed service, $W_{i}$, in conjunction with labor, $X_{\mathrm{L} i}$, and other fixed inputs, $Z_{\mathrm{P} i}$, to produce a vector of commodities, $Y_{\mathrm{P} i}$ for market and domestic uses. Both the watershed service and labor are assumed to exhibit positive marginal productivity within the relevant production range. $W_{i}$ is considered a fixed input in either home production of final services which yield utility (household production theory) or agricultural production (production theory). For example, under household production theory, households may combine goods such as water (from the streams in watersheds) and labor to provide a service such as drinking or cooking, which enhances utility. By comparison, conventional production theory would conceptualize streams (raw material) and labor as inputs in the production of water as an output that could then be sold or consumed. The relationship between the non-marketed $W_{i}$ and market commodities, $X_{\mathrm{L} i}$ and $Y_{\mathrm{P} i}$, fall under one of three general categories: complements, substitutes, or differentiated goods (Freeman, 1993). The definitions of the three categories are: (a) complementarity: the degree to which $X_{i}$ (or $Y_{\mathrm{P} i}$ ) is used (or produced) together with $W_{i}$ in the production process, e.g., inputs such as labor and land are complements to the watershed service in agricultural production; (b) substitutability: the degree to which individual inputs (or combinations of inputs) can substitute for $W_{i}$ in the production of $Y_{i}$, e.g., additions of chemical fertilizers can potentially compensate for soil erosion; (c) differentiated goods: the amount of $W_{i}$ embodied in or attached to a market good, $Y\left(W_{i}\right)$ or $X\left(W_{i}\right)$, is one of its differentiating characteristics, e.g., land quality (and therefore land value) is characterized by the extent of its susceptibility to droughts.

Knowledge of Eq. (2) would enable calculation of changes in production, $\Delta Y_{\mathrm{P} i}$, that result from changes in watershed services, $\Delta W_{i}$. Models from agronomy and household production economics can be used to describe the bio-physical production relationship between the inputs $\left(W_{i}, Z_{\mathrm{P} i}, X_{\mathrm{L} i}\right)$, and $Y_{\mathrm{P} i}$ and to deduce the production possibilities available to the household (Point, 1994). In the case of agricultural production, agronomic analyses use: (1) systematization of observed yield, or (2) statistical analysis of observed yield or (3) bio-physical simulations to estimate yield as a function of soil or hydrologic properties (Lutz, 1993).

In Stage 3 of Fig. 1 the economic value of a watershed service, $V_{i}$, is determined in terms of market value of household commodities produced or used in conjunction with the watershed service (Eq. (3)). We will need to monetize the gains in household utility that results from the increased availability of the watershed service. Models from welfare economics can be used to express the money metric of utility changes $\left(V_{i}\right)$ in terms of expenditures changes, $\Delta e_{i}$, that will depend on the utility level and therefore consumption choices (Freeman, 1993). Note that household consumption $Y_{\mathrm{C} i}$, and home time, $X_{\mathrm{H} i}$, determine the level of economic well being, i.e. utility level of $U_{i}$ that is embedded in the definition of the expenditure, $e_{i}$, given below.

$$
\text { Stage 3: } \quad \begin{aligned}
V_{i}= & \Delta e_{i}\left(P_{\mathrm{Y}}, P_{\mathrm{L}} ; U_{i}\left[X_{\mathrm{H} i}, Y_{\mathrm{C} i}\right]\right. \\
& \left.\times Z_{\mathrm{P} i}, W_{i}, H_{\mathrm{h} i}, E_{i}\right) \\
= & \Delta \pi_{i}\left(P_{\mathrm{Y}}, P_{\mathrm{L}} ; Z_{\mathrm{P} i}, W_{i}\right)
\end{aligned}
$$

These choices are directly or indirectly driven by market prices for all outputs and inputs, $P_{\mathrm{Y}}$ and $P_{\mathrm{L}}$, levels of watershed service, $W_{i}$, other fixed inputs in production and consumption, $Z_{\mathrm{P} i}$ and $H_{\mathrm{h} i}$, and exogenous income, $E_{i}$. Thus $V$ is a function of all exogenous variables listed above. Watershed services are valuable because they are expected to increase utility (and profits). If markets are complete, it can be calculated as profit increases, $\Delta \pi_{i}$ (Pattanayak and Mercer, 1998; 
Pattanayak and Kramer, 2001a). The change in expenditures $\left(\Delta e_{i}\right)$ or profits $\left(\Delta \pi_{i}\right)$ results from changes in production, $\Delta Y_{i}$, caused by changes in levels of watershed services, $\Delta W_{i}$.

\subsection{Empirical implementation}

Empirical application of the proposed three-stage framework suggests the need for at least three kinds of data for valuation purposes. First, we need forest hydrology and soils data to index the watershed service. Second, technical production data is critical to link the index of watershed services to economic activities. Finally, economic preference and price data is necessary to quantify changes in production possibilities and therefore value watershed services. Statistical variation in each of the three kinds of data is necessary to estimate and calibrate parameters of the three functions associated with each of the three stages.

Changes in household shadow prices (see case study below) or profits can provide the value of watershed services that we seek. There are nevertheless several maintained hypothesis underlying this strategy.

First, this approach assumes the analyst has access to indices of watershed services that vary over space or time, as exemplified by the Manggarai case study in Section 3. Second, this approach chooses the dual (shadow prices or profit function) over the primal (production function) representation of the production technology. By using profit functions, we can obtain both theoretically correct measures and empirically meaningful insights without explicitly estimating the econometrically more problematic production functions only when data are sufficient for calculation of profits (Diewert, 1974). This strategy of using dual functions reduces the three-stage framework to a two-stage model by combining stages two and three.

Third, our example considers the case in which watershed protection directly results from a public policy that is exogenous to the hydro-economic system and the individual households. Even though the framework suggests sequential links between the land use policy and the welfare effects, the system could be simultaneous in that the welfare change (last box) may influence the land use choice (first box). We return to a discussion of an alternative approach in Section 4.

Fourth, the basic model assumes the existence of complete markets for the commodity related to the wa- tershed service, e.g. labor, rice, coffee, fertilizers, etc. The value of watershed service is revealed in terms of market values of these commodities (see Pattanayak and Kramer (2001a) for additional discussion of this issue). When markets are incomplete, additional information on the household is necessary to identify structural equations or endogenous prices (Bockstael and McConnell, 1983).

Fifth, the model imposes a short run static perspective, i.e., household choices are not influenced by natural and financial capital allocations over time. While dynamic issues are potentially important, they cannot be addressed effectively with the data typically available. Sixth, the model assumes away general equilibrium price effects and considers the individual household to be a price taker. This is reasonable for the case study presented in the next section because the geographical impact of watershed protection is limited and the individual farmer is small in comparison to the markets in which the goods are traded.

\section{The case of drought mitigation in Manggarai, Indonesia ${ }^{1}$}

Since Dutch colonial rule, the forests of the Manggarai region on Flores island have enjoyed conservation levels that vary across watersheds. In 1993, the government of Indonesia established Ruteng Park on 32,000 ha with the primary goal to prevent further deforestation threats, initiate reforestation and land conservation, and enhance watershed protection. A recent evaluation of water resources in the region finds that the forests provide drought mitigation service by protecting streams and rivers (Binnies, 1994). We apply the three-stage framework because though there is substantial bio-physical evidence of the drought mitigation services of Ruteng Park to the downstream farmers, the economic values of this service are unknown.

\footnotetext{
${ }^{1}$ This case study draws on a presentation made by the author at the Association of Environmental and Resource Economists Workshop on "The Economic Analysis of Ecosystems" in Annapolis (MD, USA) in 1997. The case study was further developed in a master's project supervised by the author at Duke University and is documented by Zurita (2000). Comments from workshop participants and Patricia Zurita are gratefully acknowledged.
} 


\subsection{Conceptual framework for valuation of Ruteng watershed services}

In Stage 1, we propose that the establishment of Ruteng Park produces drought mitigation that is measured as a change in baseflow. Baseflow is the non-episodic residual streamflow that is left over after rain has gone out of the hydrological system in the form of either stormflow (runoff) or evapotranspiration. The forest hydrology literature posits that extensive tree cover helps maintain baseflow levels in areas with environmental characteristics similar to Ruteng, i.e. steep terrain, intense rainfall, and clayey and compacted soil (Bonell and Balek, 1993). Two forest hydrology studies in addition to the Binnies' study suggest that in many Manggarai watersheds, forests are net producers of baseflow. First, research by a local non-governmental organization finds that during the previous 25-year period, flow has decreased in 9 out of 10 streams studied in regions of Manggarai that are experiencing deforestation (Swiss Intercooperation, 1996). Second, analysis of cross-sectional variation in hydrological, topographic, and vegetation data from the 37 principal watersheds within Ruteng Park shows that reforestation can increase ground water replenishment and springs and river discharge during the dry period (Priyanto, 1996). The park management believes that "revegetation for water conservation will reduce runoff during the rainy season and increase infiltration" (Indonesian Ministry of Forestry, 1995, vol. 2, p. 5).

In Stage 2, the one economic role of baseflow is as a fixed input in the consumption of water for domestic purposes such as drinking, cooking, cleaning, bathing, etc. In the absence of a piped water infrastructure, households invest their labor in collecting water from streams for domestic purposes. In this context, baseflow can be conceived as a form of 'natural' water utility because improved services (greater availability) reduce the labor requirements for households. This case exemplifies the household production model discussed in Section 2.1 and illustrated by Gerking and Stanley (1986).

Finally in Stage 3, the opportunity cost of the time spent in collecting water or its 'shadow price' reflects the economic welfare impacts on households around Ruteng Park. The label 'shadow' prices suggest these are the hidden costs of a resource constraint (Dasgupta,
1996). Nevertheless, they represent real costs to the households that can be lowered by increased availability of water or baseflow, in this case (Dasgupta, 2001). Thus, the change in opportunity cost of collection is a measure of the value of drought mitigation, which is one of several potential benefits (and costs) of a large forest park such as Ruteng. We estimate a model of water collection cost-a type of a hedonic cost function-to implement this framework.

\subsection{Data collection}

The empirical model is based on secondary environmental statistics that describe the hydrological situation in the study area and household survey information on the economic activities of the Manggarai people. The hydrological analysis is based on data from: (1) regional soil and water conservation departments that supplied information on evapotranspiration, interception, stormflow, and ground water recharge; (2) precipitation records from the regional meteorological department; (3) topographic, vegetation, and soils data from the national ministries of public works and agriculture. A water balance model was used to derive baseflow volumes for 37 sub-watersheds in the buffer zone of the park. Calculations of evapotranspiration, interception, stormflow, and ground water recharge, which correspond to current land use, are combined with precipitation records to simulate the annual baseflow volume in each of 37 watersheds (Priyanto, 1996). This cross-sectional variation in current baseflow is sufficient to econometrically establish the influence of baseflow on water collection costs.

The household data are drawn from a socio-economic survey conducted in the Manggarai area in 1996 as part of a larger project on the economic analysis of protected areas (Kramer et al., 1997a). Because the hydrological effects of the park dissipate over geographical distance, the study area was restricted to the 47 villages in the buffer zone of Ruteng Park, contiguous to the protected area. Of the 13,700 farming households in the buffer zone, 500 were chosen on the basis of stratified random sampling in which the weights reflected the population density of the villages.

The average Manggarai household has little education and wealth. They exhibit a heavy reliance on agriculture. The $87 \%$ of the local people are employed 
in agriculture, in their own or other's farms and non-agricultural employment includes local government, NGOs, kiosks, and logging crews. The statistics on both hiring-in and hiring-out labor, the fact that a large proportion of households report input and output prices, and the proximity of roads and other market infrastructure (e.g. stores and credit facilities), and the statistical tests reported by Pattanayak and Kramer (2001a) provides some evidence that markets are complete for agricultural products and labor. The Manggarai farm on land parcels that are small, steep, and not irrigated. While the Manggarai region receives on average $2.5 \mathrm{~m}$ of rainfall annually, only about $40 \%$ stays in the system as baseflow (a more appropriate drought measure)—suggesting that many sub-watersheds experience drought situations during the dry season.

\subsection{Econometric model of water collection cost}

Our empirical analysis focuses on the relationship between opportunity costs of water collection and baseflow, and thus, the water collection cost function is the key estimated relationship. The dependent variable is the cost of a typical water collection trip, $C_{i}$, measured in terms 'time per round trip' multiplied by the weighted wage rates of family members who collect (see Pattanayak et al. (2004) and MacDonald et al. (2001) for a similar computation). This data was available for 392 households. The independent variables are household characteristics and fixed inputs, including baseflow. Household characteristics such as average education and illness levels are included to capture household choices of who to send for collection and how far to go, both of which affect the opportunity costs. We include six region specific dummy variables to measure impacts of fixed inputs. Since different interviewer teams administered surveys in different regions of the buffer zone, these dummy variables could as well reflect interviewer effects. Nonetheless, our intention is to control for these 'nuisance' parameters that would otherwise confound the signals related to our primary variable of interest-baseflow. The estimation of a price as a function of environmental characteristics is common to environmental economics, and in this sense our case study is an example of a hedonic cost model. Our central goal is to statistically evaluate how base-
Table 1

Fixed-effects regression analysis of water collection costs in Manggarai households

\begin{tabular}{|c|c|c|}
\hline & Coefficient & $P$-value \\
\hline Average education (years) & -3.31 & 0.814 \\
\hline Average number of illness (count) & 31.05 & 0.059 \\
\hline Annual baseflow (mm) & -0.30 & 0.004 \\
\hline $\begin{array}{l}\text { Region-team dummy }(1=\text { region } 1 \\
0=\text { otherwise })\end{array}$ & -326.07 & 0.000 \\
\hline $\begin{array}{l}\text { Region-team dummy }(1=\text { region } 2 \\
0=\text { otherwise })\end{array}$ & -86.69 & 0.068 \\
\hline $\begin{array}{l}\text { Region-team dummy }(1=\text { region } 3 \\
0=\text { otherwise })\end{array}$ & -95.09 & 0.003 \\
\hline $\begin{array}{l}\text { Region-team dummy }(1=\text { region } 4 \\
0=\text { otherwise })\end{array}$ & 103.36 & 0.013 \\
\hline $\begin{array}{l}\text { Region-team dummy }(1=\text { region } 5 \\
0=\text { otherwise })\end{array}$ & -250.73 & 0.000 \\
\hline $\begin{array}{l}\text { Region-team dummy }(1=\text { region } 6 \\
0=\text { otherwise })\end{array}$ & -235.55 & 0.000 \\
\hline Regression constant & 654.87 & 0.000 \\
\hline Number of observations & 392 & \\
\hline Adjusted $R^{2}$ & 0.34 & \\
\hline$F$-statistic $(9,382)$ & 23.27 & 0.000 \\
\hline
\end{tabular}

flow impacts water collection costs, controlling for a variety of other factors. In this regard, the use of the fixed-effects model allows us to retain a parsimonious specification, without introducing significant omitted variable bias.

Results of the estimated model are reported in Table 1 . As shown by the model statistics, the overall model is statistically significant and has reasonable fit for a small cross-sectional data set, explaining $35 \%$ of the variation. We find the expected result that households with higher illness rates have higher costs, offering some evidence of the complementarities of health and environment. The significance of the region-team dummies reflects the differences in the collection costs across regions. Instead of dwelling on these differences, we focus on the economic impacts of ecosystem services-the baseflow coefficient. We find that it is negative and significant, lending support to our central hypothesis that watershed services can improve livelihoods, in this case by lowering the costs of water collection for domestic water uses. For example, the estimated coefficient suggests that a $100 \mathrm{~mm}$ increase in baseflow (10\% increase from current levels) can lower per trip collection costs by 30 Indonesian rupiahs. We conduct some illustrative simulations below to further examine this result. 


\subsection{Discussion of Manggarai case study}

We need estimates of projections of the baseflow levels that will result from forest protection and regeneration in Ruteng Park to fully evaluate these results. Unfortunately, these were not available from the hydrologic analysis. Instead of evaluating a hypothetical baseflow change, we rely on a exploratory forest hydrology model described by Pattanayak and Kramer (2001a,b) to predict baseflow by analyzing the cross-sectional hydrological data. Projected increase in baseflow levels from 25 to $50 \%$ increases in forest cover (bounded above by $100 \%$ forest cover) in nine Manggarai counties (kecamatans) are reported in Table 2 (columns 4 and 5). Baseflow can decrease even as forest cover increases because of the mixed influences of forest conditions, topography, climate and land use peculiar to some watersheds. Assuming one water collection trip per day, we multiply these predicted baseflow changes with the per trip savings in collection costs for each household in our sample to construct an estimate of the annual savings in water collection costs. These are reported per household per year for nine counties in Table 2 (columns 6 and 7).

The distribution of costs savings across counties offers three insights. First, increased forest cover will not necessarily increase baseflow (mitigate drought conditions) for all households in all watersheds. Second, there is a spatial pattern to the drought mitigation. The wetter watersheds (in P. Borong, Borong, Ruteng, and Satarmese) that are frequently exposed to moist winds from the southern seas and continually shrouded by cloud cover (Binnies, 1994), consistently realize positive drought mitigation from increases in forest cover. Perhaps in these moist watersheds, trees are less competitive with agricultural crops. Finally, where increased watershed protection mitigates droughts, the savings in water collection costs can be sizeable.

This case study shows that hydrological modeling can be combined with micro-econometric techniques to value drought mitigation provided by forested watersheds in an agrarian region of Indonesia. The multidimensional hydrological service is made analytically tractable by approximating it as a change in baseflow. Spatial variation in current baseflow is used in econometric models to estimate a value of the drought mitigation as the marginal savings in water collection costs to households in the affected watersheds. The estimated coefficients on the baseflow variable in a fixedeffects model of water collection costs, validate the central hypothesis that additional baseflow can lower real, though typically hidden, costs to the households. If our baseflow prediction model is correct, however, then it suggests that forest protection will not always generate cost savings because baseflow will decrease for some households. The message for policy makers and local managers is that they should consider a selective approach targeting specific watersheds for forest conservation to fulfill the management goals of providing watershed protection benefits (Indonesian Ministry of Forestry, 1995). Given that the baseflow prediction module of our study is an exploratory attempt to model bio-physical features, a more rigorous forest hydrological analysis is necessary to identify the

Table 2

Savings in water collection costs from baseflow increases in Manggarai

\begin{tabular}{|c|c|c|c|c|c|c|}
\hline \multirow[t]{2}{*}{ Kecamatan (county) } & \multirow[t]{2}{*}{$\begin{array}{l}\text { Baseline } \\
\text { baseflow (mm) }\end{array}$} & \multirow[t]{2}{*}{$\begin{array}{l}\text { Baseline forest } \\
\text { cover }(\%)\end{array}$} & \multicolumn{2}{|c|}{$\begin{array}{l}\text { Baseflow change } \\
(\mathrm{mm})\end{array}$} & \multicolumn{2}{|c|}{$\begin{array}{l}\text { Savings in water } \\
\text { collection costs }^{\mathrm{a}}\end{array}$} \\
\hline & & & $25 \%$ & $50 \%$ & $25 \%$ & $50 \%$ \\
\hline Borong & 1071 & 75 & 16 & 19 & 1724 & 2084 \\
\hline Elar & 1075 & 48 & -17 & -20 & -1886 & -2180 \\
\hline Langke Rembong & 904 & 27 & -25 & -44 & -2803 & -4838 \\
\hline Pembantu Borong & 870 & 71 & 9 & -3 & 959 & -284 \\
\hline Pembantu Elar & 1043 & 88 & 24 & 24 & 2669 & 2669 \\
\hline Pembantu Lambaleda & 1144 & 50 & -23 & -45 & -2599 & -5052 \\
\hline Pembantu Ruteng & 904 & 59 & -12 & 0 & -1372 & -2 \\
\hline Ruteng & 848 & 56 & 16 & 16 & 1773 & 1773 \\
\hline Satarmese & 816 & 85 & 9 & 16 & 981 & 1773 \\
\hline
\end{tabular}

\footnotetext{
${ }^{a}$ Median in Indonesian rupiahs for the set of sampled households within the county.
} 
precise bio-physical factors that condition the relationship between forest protection and baseflow. It is worth reiterating that regardless of the mechanism that effectively mitigates drought, it is clear that increases in baseflow can generate real savings for households who spend time and effort in collecting water for domestic uses. Finally, we clarify that the value of drought mitigation constitutes just one element in the calculation of the net present value of the overall integrated conservation and development project for Ruteng Park. Thus, the net impact of reforestation may be positive in all counties, when a full suite of benefits are taken into account.

\section{Discussion of valuation methodology}

This section draws on the application of this approach in the Indonesian case study described above and in (Pattanayak and Kramer, 2001a), a study of soil conservation from agroforestry in the Philippines (Pattanayak and Mercer, 1998) and other literature to highlight the methodological lessons.

\subsection{Generalizing the conceptual framework}

The three-stage conceptual framework described in Section 2 organizes the valuation of watershed services in terms of changes in economic welfare (money measure of utility change). The framework presents a unified way to measure the economic value of watershed services as they contribute to economic activities. This is evaluated by considering the framework's usefulness in the context of different classes of services, institutional settings, and valuation methods. In all cases the primary influence of the watershed service is assumed to be on economic production activities-be that household production or traditional production.

The first class of services is desirable service flows such as sediment and flood control (Kramer et al., 1997b), water purification, nutrient recycling, and microclimate stabilization. The second class is comprised of watershed pollution flows (essentially negative externalities) which have been considered in studies using dose-response (Freeman, 1979) and duality (Garcia et al., 1986; Kopp et al., 1985). A final class of services include collection of water, fuelwood, and minor forest products, as well as the hunting and fishing activities of agrarian and pastoral communities. Any of these three classes of services could be addressed with a similar framework.

Although this framework lacks provision for feedback effects between farmers and their natural environment across time, it is useful under certain circumstances. Because biogeochemical processes are slow relative to human time frames and humans exhibit positive time preference, some of the feedbacks between human induced land uses and the delivery of the watershed service can be safely ignored. This is particularly true of those feedbacks that occur in a 'second round' (currently) as the environment responds to changes in human activity caused by changes in their environment. An example of such model simplification is the use of the time lag variable in an agroforestry study (Pattanayak and Mercer, 1998). The variable relates the history of agroforestry to current soil condition and agricultural profits, thus explicitly incorporating the impact of previous agroforestry and farming, but effectively ignoring the impact of current agroforestry and farming, on current soil conditions and profits.

This framework can be used for valuation of watershed services in a variety of institutional settings, ranging from national protection of the environment to village management of common pool watersheds. The first box in the three-stage diagram (Fig. 1) is not limited to a policy choice, but could represent a variety of institutional arrangements (policy scenarios, market structures, and property rights arrangements) which generate watershed services, behavioral responses and welfare changes. Freeman (1993) provided a broad discussion of several policy questions that can be addressed with this framework. Finally, within the conceptual framework, several methods can be used to value watershed services, including but not limited to the hedonic cost function method used in the Indonesian example. Below we discuss how other methods can be utilized to value watershed services.

\subsection{Indexing the watershed service}

The specific index of the watershed service must be carefully defined for the following three reasons. First, the definition of the variable influences the choice of the functional form in estimating economic values as 
a function of the watershed variable. Drought mitigation in Indonesian study is measured in terms of annual baseflow. Given that baseflow is a level (not incremental or change) and water is an essential input in domestic consumption, baseflow can be linearly or non-linearly related to shadow prices. In the analysis of soil conservation benefits in the Philippines by contrast, the soil variable is an incremental measure of the farmers' perceived changes in soil attributes. These incremental changes are not necessary for continued agricultural production in the short run, i.e. if the soil condition does not improve, the farmer can still produce some positive amount of crop. Therefore, the soil variable can enter the profit function in an additive manner implying non-essentiality.

Second, spatial variation in the watershed variable allows us to estimate a function that can predicted changes in the watershed service as a consequence of public or private land use changes. Absent such predictions, measurement of values of watershed services would be limited to marginal costs estimated from cross-sectional variation in current levels of the watershed service. Finally, only one dimension of the hydrological service, annual baseflow, is used in the Indonesian study. By contrast, the Filipino study combines changes in four attributes of soil quality (depth, color, texture, and fertility) by experimenting with various indices. While the results are robust across indices in general, the soil conservation values are larger for the multiplicative indices than for the linear indices. This indicates input from an agronomist on the relationship between yield and soil quality is critical. Without such input, the analyst must report a wider range of values.

\subsection{Applying different valuation methods}

We could use other methods to value watershed services, in addition to the hedonic costs function, for at least three reasons. First, the results obtained with other methods can be compared and used to judge the robustness of the conceptual framework. Second, the literature and the Indonesian data suggest that watershed services are multi-dimensional. Different methods are most appropriate for valuation of different uses of the watershed services. Finally, because some elements of watershed services have gender specific users, the alternative method (e.g. travel cost) may shed light on the significance of intra-household differences.

In the case study presented in Section 3, watershed services in the form of baseflow affects household production of water for domestic uses. These services could impact agricultural production as well. Pattanayak and Kramer (2001a) show that the estimation of agricultural profits as a function of baseflow and other variables provides a complementary measure of the economic value of watershed services.

In Section 2 we showed that the value of a watershed service is the money equivalent of a change in utility or in effect a "willingness to pay" (WTP) amount. Pattanayak and Kramer (2001b) showed that agricultural households can be directly questioned to elicit their WTP for drought mitigation using contingent valuation $(\mathrm{CV})$ surveys. In CV methodology, values are elicited by first describing a proposed (hypothetical) service and its market to survey respondents and then asking them directly to state their WTP for the proposed service. In the case of watershed services, the link between WTP and profits guides the specification of WTP models, including the choice of independent variables such as input and output prices and fixed inputs. Pattanayak (2000) uses the CV method in addition to the profitability method to estimate the worth of drought mitigation in Indonesia and finds inconclusive evidence regarding the convergence of values from the two methods (without clear evidence in favor of any one method).

Averting expenditure methods can also be used to estimate changes in welfare due to ecosystem inputs. Annual expenditures on irrigation in the Indonesian data or on fertilizers and pesticides in the Filipino data result partly because of water and soil fertility constraints. Through the process of natural irrigation and natural fertilization, the watershed services would lower 'averting expenditures' on irrigation and fertilizers and thus generate savings. Such an approach would also provide information on the degree of economic substitution between natural watershed services and human-made agricultural inputs.

\subsection{An agenda for future research}

The discussion so far also generates some insights for enhancing the policy toolkit and for refining the model structure. Although household and sample level 
values of watershed services are desirable policy information, their usefulness is limited to the socioeconomic and geographic context in which the values are derived. Given the costs of conducting new research for site-specific environmental resources, careful value or benefits transfers offer a resource-saving way to transfer benefit estimates from one site to another geographically and socio-economically similar site (Brookshire and Neill, 1992). To successfully transfer benefit estimates, an analyst must (a) identify key features of this analysis which must be matched when extrapolating to other sites, and (b) provide transferrable values by combining the results of this analysis with the broader empirical literature on estimated values of watershed services. Unfortunately, the typical transfer of benefits or values has been criticized for failing to satisfy basic theoretical requirements concerning income constraints and substitution effects. Smith and Pattanayak's (2002) proposal for 'structural meta-analysis' presents one approach for estimating or calibrating a value function of watershed services in a manner consistent with economic theory.

A related issue is the need to consider inter-household heterogeneity when aggregating unit values, measured for the typical or average household, over the entire affected population. There are at least two ways to take inter-household differences, for example between income groups, into account: (a) use household specific weights, as some function of income, for a weighted aggregation; (b) re-estimate the models with additional interaction terms that allow income levels to influence the effect of watershed services on collection costs. Such careful attention to inter-household differences would increase confidence in transferring values of watershed services.

Given the spatial nature of the watershed services, econometric refinements of the error structure of the estimated models, by correcting for any spatial lag and or autocorrelation, may improve the parameter estimates (Pattanayak and Butry, 2003). The correlation of errors across space could occur in many ways including the simple case of watershed contiguity and more complicated patterns based on rainfall levels (iso-hytes), elevation (contour lines) and road connections.

Relaxing two critical assumptions of the agricultural household model could allow the model to reflect two fundamentally different "world views" regarding risk and intra-household heterogeneity. Watershed protection could influence the probability distribution of the watershed variable. Risk can be considered in the framework by (a) incorporating entire distributions, rather than single point mean measures, of the watershed and other key economic variables in the system, and (b) characterizing households' attitudes towards risk, possibly derived from some behavioral traits (e.g. investments in irrigation) or opinions (e.g. about their future). The second modification would entail replacing the basic economic unit as a single consensual and efficient household with a household that is a grouping of men, women, and children. Household members may have different objectives and choices that are guided by the intra-household distribution of endowments and by traditions vested by the prevalent culture, rather than just an efficiency criterion (Strauss and Thomas, 1995). Because allocations within households may no longer be efficient, there may no longer be a single household water collection cost, but a distribution of individual costs, which may not maximize welfare due to the constraints imposed by prevalent culture. An important research question would be whether spatial autocorrelation, risk and intra-household considerations are significant in terms of the estimated values, i.e. what is the nature and extent of the bias. Clearly, quantitative evidence on the extent of the bias will be available only if data on the spatial error structure, the probability distributions of all relevant factors and the criteria for intra-household allocations are available.

\section{Conclusion}

Few rigorous empirical studies have analyzed the downstream economic benefits of watershed protection. By developing an organizing framework, finding credible estimates of values for a watershed service, and offering lessons for researchers at all stages of data collection and analysis, this paper addresses the neglected, but critical, question of the importance of watershed services to farming communities. A case study from Flores, Indonesia provides evidence of a substantive, quantified economic benefit of watershed service based on a hedonic regression model of water collection costs. We want to be clear that the reported 
estimates are indicative rather than precise and absolute values of a complex ecosystem service. The paper also generates a research agenda for enhancing the policy analysis toolkit. Ultimately, valuing watershed services can help to protect the world's fast deteriorating tropical forest ecosystems by providing critical input into the evaluation of a whole host of policies and programs for conservation and development in the tropics, thereby allowing us to "give the invisible hand of free market economics a green thumb" (Wilson, 1993, p. 283).

\section{Acknowledgements}

This paper is drawn from Chapter 5 in the author's $\mathrm{Ph} . \mathrm{D}$. dissertation completed at Duke University. The author gratefully acknowledges comments from Erin Sills, Sampurno Bruijnzeel, Tom Tomich, Randy Kramer, and seminar participants at 1999 ICRAF Methodology Workshop on Environmental Services and Land Use Change (Chiang Mai, Thailand, June 1999). Asian Development Bank provided partial financial support for data collection and Patricia Zurita provided research assistance.

\section{References}

Binnies, 1994. Master Plan Report: Integrated Water Resources in Flores Island, Indonesia, vol. 2. Directorate General of Water Resources Development, Ministry of Public Works, Indonesia.

Bockstael, N., McConnell, K., 1983. Welfare measurement in the household production framework. Am. Econ. Rev. 73, 806-814.

Bonell, M., Balek, J., 1993. Recent scientific developments and research needs in hydrological processes of the humid tropics. In: Bonnell, M., Hufschmidt, M., Gladwell, J. (Eds.), Hydrology and Water Management in the Humid Tropics. UNESCO/Cambridge University Press, Cambridge, UK, pp. 67-243.

Brookshire, D., Neill, H., 1992. Benefit transfers: conceptual and empirical issues. Water Resour. Res. 28, 651-655.

Bruijnzeel, L.A., 1990. Hydrology of Moist Tropical Forests and Effects of Conversion: A State of Knowledge Review. IAHS, Netherlands.

Burt, O., 1981. Farm level economics of soil conservation in the Palouse area of the northwest. Am. J. Agric. Econ. 63, 83-92.

Clark, E., Haverkamp, J., Chapman, W., 1985. Eroding Soils: The Off-site Impacts. The Conservation Foundation, Washington, DC.

Crosson, P., Stout, A., 1983. Productivity Effects of Cropland Erosion in the United States. RFF, Washington, DC.
Dasgupta, P., 1996. The economics of the environment. Environ. Dev. Econ. 1, 387-428.

Dasgupta, P., 2001. Human Well Being and the Natural Environment. Oxford University Press, Oxford, UK.

Diewert, W., 1974. Applications of duality theory. In: Intrilligator, M., Kendrick, D. (Eds.), Frontiers of Quantitative Economics, vol. II. North-Holland, Amsterdam, pp. 106-171.

Dixon, J., 1997. Analysis and management of watersheds. In: Dasgupta, P., Goran-Mäler, K. (Eds.), The Environment and Emerging Development Issues, vol. I. Clarendron Press, Oxford, pp. 371-398.

Doolette, J., Magrath, W. (Eds.), 1990. Watershed Development in Asia: Strategies and Technologies. Technical Paper No. 127, The World Bank, Washington, DC.

Easter, K., Dixon, J., Hufschmidt, M. (Eds.), 1986. Watershed Resources Management: Studies from Asia and the Pacific. Westview Press, Inc., Boulder, CO, USA, 222 pps.

Easter, K., Dixon, J., Hufschmidt, M. (Eds.), 1990. Watershed Resources Management: Studies from Asia and the Pacific. East-West Center, Honolulu, Hawaii.

Eckstein, O., 1958. Water Resource Development: The Economics of Project Evaluation. Harvard University Press, Cambridge.

Freeman, A., 1996. On valuing the services and functions of ecosystems. In: Simpson, R., Christensen, N. (Eds.), Human Activity and Ecosystem Function: Reconciling Economics and Ecology. Chapman \& Hall, London, UK, pp. 241-255.

Freeman, A., 1993. The Measurement of Environmental and Resource Values: Theory and Methods. Resources for the Future, Washington, DC.

Freeman, A., 1979. The Benefits of Environmental Improvement. Resources for the Future, Washington, DC.

Garcia, P., Dixon, B., Mjelde, J., Adams, R., 1986. Measuring the benefits of environmental changes using a duality approach: the case of ozone and Illinois cash gain farms. J. Environ. Econ. Manage. 13, 69-80.

Georgiou, S., Whittington, D., Pearce, D., Moran, D., 1997. Economic Values and the Environment in the Developing World. Edward Elgar, Cheltenham, UK.

Gerking, S., Stanley, L., 1986. An economic analysis of air pollution and health: the case of St. Louis. Rev. Econ. Stat. 68, $115-121$.

Gregersen, H., Brooks, K., Dixon, J., Hamilton, L., 1987. Guidelines for Economic Appraisal of Watershed Management Projects. FAO Conservation Guide No. 16, Rome.

Hamilton, L., King, P., 1983. Tropical Forested Watersheds: Hydrologic and Soils Response to Major Uses or Conversions. Westview Press, Boulder.

Haveman, R., 1972. The Economic Performance of Public Investments: An Ex-Post Evaluation of Water Resource Investments. Johns Hopkins University Press, Baltimore.

IIED, 1994. Economic evaluation of tropical forest land use options: a review of methodology and applications. Unpublished Report. International Institute for Environment and Development, London.

Indonesian Ministry of Forestry, 1995. Integrated Conservation Management Plan for Ruteng Nature Recreation Park: 19952020, vols. I and II. Directorate General of Forest Protection and Nature Conservation, Jakarta. 
Kopp, R., Vaughan, W., Hazilla, M., Carson, R., 1985. Implications of environmental policy for US agriculture: the case of ambient ozone standards. J. Environ. Manage. 20, 321-331.

Kramer, R., Pattanayak, S., Sills, E., Simanjuntak, S., 1997a. The economics of the Siberut and Ruteng protected areas. Final Report Submitted to the Directorate General of Forest Protection and Nature Conservation, Ministry of Forestry, Republic of Indonesia. Nicholas School of the Environment, Durham.

Kramer, R., Richter, D., Pattanayak, S., Sharma, N., 1997b. Economic and ecological analysis of watershed protection in eastern Madagascar. J. Environ. Manage. 49, 277-295.

Krutilla, J., Eckstein, O., 1958. Multiple Purpose River Development: Studies in Applied Economic Analysis. Resources for the Future. John Hopkins Press, Baltimore.

Lal, R., 1993. Challenges in agriculture and forest hydrology in the humid tropics. In: Bonnell, M., Hufschmidt, M., Gladwell, J. (Eds.), Hydrology and Water Management in the Humid Tropics. UNESCO/Cambridge University Press, Cambridge, UK.

Lutz, E. (Ed.), 1993. Toward Improved Accounting for the Environment. The World Bank, Washington, DC.

Lynne, G., Conroy, P., Prochaska, F., 1981. Economic valuation of marsh areas for marine production processes. J. Environ. Econ. Manage. 8, 175-186.

Maas, A., Hufschmidt, M., Dorfman, R., Thomas Jr., H., Marglin, S., Fair, G., 1962. Design of Water-Resource Systems: New Techniques for Relating Economic Objectives, Engineering Analysis, and Government Planning. Harvard University Press, Cambridge, MA.

MacDonald, D., Adamowicz, W., Luckert, M., 2001. Fuelwood collection in northeastern Zimbabwe: Valuation and calorific expenditures. Journal of Forest Economics 7 (1), 29-52.

Magrath, W., Arens, P., 1989. The Cost of Soil Erosion on Java: A Natural Resource Accounting Approach. Environment Department Working Paper No. 15. The World Bank, Washington, DC.

Mäler, K., 1991. The production function approach in developing countries. In: Vincent, J., Crawford, E., Hoehn, J. (Eds.), Valuing Environmental Benefits in Developing Economies, Seminar Proceedings, Michigan State University Graduate Specialization in Resource Economics, East Lansing, Michigan.

Moore, I., Grayson, R., Ladson, A., 1991. Digital terrain modelling: a review of hydrological, geomorphological, and biological applications. Hydrogical Process. 5, 3-30.

Pattanayak, S., Butry, D., 2003. Complementarity of Forests and Farms: Accounting for Ecosystem Services. Working Paper 02_01R. Research Triangle Institute, North Carolina.
Pattanayak, S.K., Sills, E., Kramer, R., 2004. Seeing the forests for the fuel. Environ. Dev. Econ. (in press)

Pattanayak, S.K., Kramer, R., 2001a. Worth of watersheds: a producer surplus approach for valuing drought control in eastern Indonesia. Environ. Dev. Econ. 6, 123-145.

Pattanayak, S.K., Kramer, R., 2001b. Pricing ecological services: willingness to pay for drought control services in Indonesia. Water Resour. Res. 37, 771-778.

Pattanayak, S.K., 2000. How Green are these Valleys? Reconciling Agricultural Production and Stated Preference Data to Account for Ecosystem Costs of Deforestation. Working Paper 00_02. Research Triangle Institute, North Carolina.

Pattanayak, S., Mercer, D.E., 1998. Valuing soil conservation benefits of agroforestry practices. Agric. Econ. 18, 31-46.

Pereira, H., 1989. Policy and Practice in the Management of Tropical Watersheds. Westview Press, Boulder.

Point, P., 1994. The value of non-market natural assets as production factor. In: Pethig, R. (Ed.), Valuing the Environment: Methodological and Measurement Issues. Kluwer, The Netherlands, pp. 23-57.

Priyanto, A., 1996. Hydrology Specialist Report on Ruteng. Directorate General of Forest Protection and Nature Conservation. Ministry of Forestry, Jakarta, Indonesia.

Ribaudo, M., 1989. Targeting the conservation reserve program to maximize water quality benefits. Land Econ. 65, 320-332.

Smith, V.K., Pattanayak, S.K., 2002. Is meta-analysis the Noah's Ark for non-market valuation. Environ. Resour. Econ. 22, 271296.

Strauss, J., Thomas, D., 1995. Human resources: empirical modeling of household and family decisions. In: Behrman, J., Srinivasan, T. (Eds.), Handbook of Development Economics. Elsevier, Amsterdam, The Netherlands, vol. 3, pp. 18832023.

Swallow, S., 1994. Renewable and nonrenewable resource theory applied to coastal agriculture, forest, wetland, and fishery linkages. Marine Res. Econ. 9, 291-310.

Swiss Intercooperation, 1996. Performance of Springs in Manggarai: Summary of Study by PDAM Ruteng, Ruteng, Flores.

Walker, D., 1982. A damage function to evaluate erosion control economics. Am. J. Agric. Econ. 64, 690-698.

Wilson, E., 1993. The Diversity of Life. W.W. Norton, New York, 424 pps.

Zurita, P., 2000. Ecosystem valuation: concepts, theories and empirics. Masters Project. Nicholas School of the Environment, Duke University, Durham, NC. 